\title{
Heritable Mass Conversion of a Mutant Penicillinase-negative Culture of Bacillus cereus to a Positive Fully De-repressed State
}

\author{
By M. R. POLLOCK AND JOAN FLEMING \\ Department of Molecular Biology, University of Edinburgh, Edinburgh, EH93JR
}

(Accepted for publication 4 September 1969)

\begin{abstract}
SUMMAR Y
A small proportion of spontaneous penicillinase-negative mutants of the penicillinase-magno-constitutive Bacillus cereus strain $569 / \mathrm{H}$ prove to be highly unstable and revert to the relatively stable magno-constitutive parent phenotype at a high rate spontaneously. If incubated at $45^{\circ}$ or at the normal growth temperature of $35^{\circ}$ with chloramphenicol $(20 \mu \mathrm{g} . / \mathrm{ml}$.) the organisms of a broth culture of this meta-stable negative strain can be induced to undergo I00 \% conversion to the fully de-repressed magno-constitutive state within 90 to $120 \mathrm{~min}$. The conversion event appears to occur at random amongst the bacilli, whether single or joined in pairs; there is little or no phenotypic lag between committal to reproduction in the derepressed state and full expression of gene potential in the form of maximal rate of penicillinase production and a 1000-fold increase in penicillin resistance. Induced conversion is inhibited by nalidixic acid (10 $\mu \mathrm{g}$. $/ \mathrm{ml}$.).

It is concluded that the conversion event, for which some possible mechanisms are discussed, is controlled by a thermo-labile protein inhibitor.
\end{abstract}

\section{INTRODUCTION}

The penicillinase-magno-constitutive Bacillus cereus mutant (strain 569/H) of the wild-type inducible strain 569 is known to be, under certain circumstances, slightly unstable and will spontaneously give rise, on prolonged subculture, to a range of variants, most of which show little or no penicillinase activity. The overwhelming majority of the penicillinase-loss mutants are genetically stable. A small proportion, however, revert to their parent (magno-constitutive) phenotype spontaneously at a very high rate.

On further analysis of one (strain $569 / \mathrm{H} / \mathrm{I} 4$ ) of these meta-stable 'negatives', it was found that conversion of the positive state could be achieved, without any significant loss in viability, in up to $100 \%$ of a culture within an hour or two by incubation either at a raised temperature of $45^{\circ}$ or at the usual growth temperature of $35^{\circ}$ in the presence of chloramphenicol.

This conversion shows similarities to phase variation in Salmonella (see Hayes, I964) and seems possibly to be analogous to 'paramutational' events in maize (see reviews by McClintock, 196I, I965; and by Brink, Styles \& Axtell, I968) and at the Pal locus in Antirrhinum (Harrison \& Fincham, 1964) as well as to certain other unstable mutational phenomena in Salmonella (Smith-Keary \& Dawson, 1964; 
Dawson \& Smith-Keary, 1963) and in Escherichia coli (Morse, 1967) and other types of variations reported in higher organisms (see Brink, 1964).

We here report the results of some studies indicating that this conversion in Bacillus cereus is under the control of a protein repressor.

\section{METHODS}

Bacterial strains. The magno-constitutive mutant $569 / \mathrm{H}$ was obtained spontaneously from the wild-type inducible Bacillus cereus NRRL569 (Kogut, Pollock \& Tridgell, I956). Four other constitutive mutant strains $(569 / \mathrm{K}, 569 / \mathrm{M}, 569 / \mathrm{L}$ and $569 / \mathrm{A})$ were also obtained spontaneously from strain 569 by a similar technique.

The unstable strain $569 / \mathrm{H} / \mathrm{I} 4$ was isolated as a penicillinase-negative mutant colony on the indicator plates described below, from a spore suspension of strain $569 / \mathrm{H}$ treated with ethylmethane sulphonate (EMS) (Dubnau \& Pollock, 1965).

The classifying terminology used for describing these enzyme mutants is that suggested by Collins, Mandelstam, Pollock, Richmond \& Sneath (I965); but bacilli or colonies of strain $569 / \mathrm{H} / \mathrm{I} 4$ in the negative or positive state (i.e. before or after conversion) are referred to respectively simply as 'micros' and 'magnos'.

Media. The liquid medium used was a I \% peptone broth (' $\mathrm{S}$ ' broth, Pollock, I953 $a$ ) and solid indicator medium (AA) was made by incorporating $\mathrm{I} \cdot 5 \%$ agar in the above and adding Andrade indicator (Kogut et al. 1956). During conversion experiments in liquid media, gelatine was added to a final concn. of $\mathrm{I} \%(\mathrm{w} / \mathrm{v})$ when turbidity reached the equivalent of between 0.02 and $0.05 \mathrm{mg}$. dry bacterial $\mathrm{wt} / \mathrm{ml}$.

Culture conditions. Unless otherwise stated, inocula were derived from standard $\left(3 \times 10^{8}\right.$ viable cells $/ \mathrm{ml}$.) spore suspensions (Pollock, I953a) first plated out on AA to produce single colonies (either overnight at $30^{\circ}$, or $24 \mathrm{hr}$ at $25^{\circ}$ ) which were subcultured at $35^{\circ}$ in ' $\mathrm{S}$ ' broth or inoculated on the surface of, or as deep layers in, AA plates.

For conversion experiments a spore inoculum from strain 569/H/14 was spread on the surface of AA in a Petri dish so as to produce single colonies. After incubation overnight at $30^{\circ}$, or for $24 \mathrm{hr}$ at $25^{\circ}$, portions from each of ten single, marked colonies were subcultured into $2.0 \mathrm{ml}$. ' $\mathrm{S}$ ' broth and shaken at $35^{\circ}$ for approx. $2 \mathrm{hr}$. The original plate was developed (see below) with penicillin to identify, and exclude, any spontaneous magnos (convertants) which might be present. One of the cultures derived from a negative colony was chosen and maintained in the logarithmic phase of growth, if necessary by serial dilutions in broth, at a concn. corresponding to about $0.05 \mathrm{mg}$. dry wt/ml., at which level (unless otherwise stated) the experiment was started.

Penicillin sensitivity of individual organisms is expressed as the lowest concentration of benzylpenicillin in AA that caused a reduction of at least $50 \%$ in the viable count from an inoculum into layered agar (Pollock, 1957).

$\beta$-Lactamase activity. Penicillinase (E.C. $3 \cdot 5 \cdot 2.6$ ) was assayed quantitatively by the Perret (1954) iodine method with benzylpenicillin as substrate and the activity expressed as units (defined by Pollock \& Torriani, r953). Samples ( $5 \mathrm{ml}$.) were kept at $0^{\circ}$ with chloramphenicol $(50 \mu \mathrm{g} . / \mathrm{ml}$.) until assayed. Cephalosporinase activities were assayed by the same method, using cephalosporin $\mathbf{C}$ as substrate, after the addition of $\mathrm{I} \cdot 67 \mathrm{~mm}$ zinc sulphate (final concentration) to allow full activation of the enzyme (Kuwabara \& Abraham, 1967). 
Analysis of populations. The proportions of micros and magnos in a suspension were determined by inoculating an appropriate broth dilution either on the surface of AA plates or into $20 \mathrm{ml}$. of molten AA at $45^{\circ}$ poured into Petri dishes and subsequently covered with $3.0 \mathrm{ml}$. of AA. The plates were then incubated overnight at $25^{\circ}$ or $30^{\circ}$.

Development. The colonies were scored by flooding the surface of the plates with approx. $5 \mathrm{ml}$. of a $10 \%(\mathrm{w} / \mathrm{v})$ aqueous benzylpenicillin solution and counting the proportion of colonies becoming red (magnos) due to recolourization of indicator by penicilloic acid. The remaining white colonies (micros) could be clearly"differentiated: surface colonies within a minute and deep colonies within about $30 \mathrm{~min}$., at room temperature.

Special materials. Chloramphenicol (Parke-Davis Ltd.), mitomycin and caffeine, anhydrous (Sigma London Chemical Co. Ltd.), Streptomycin sulphate B.P. (Glaxo Ltd.) and nalidixic acid (Winthrop Laboratories) were purchased as commercial preparations. Cephalosporin C (as sodium salt) was a gift from Glaxo Research Ltd.; actinomycin D was a gift from Merck, Sharp and Dohme Ltd. and 5-fluorodeoxyuridine (FUDR) a gift from Roche Products Ltd. We acknowledge these gifts with gratitude.

Viable counts. Viable organisms were counted by deep inoculation of appropriate broth dilutions into AA. Mean counts from two dilutions (differing by 2 - or $2 \frac{1}{2}$-fold) were taken when absolute counts were required. In some experiments only the proportion of magno or micro colonies developing after surface inoculation was scored, counting a total of Ioo colonies within one area of the plate.

In experiments with the addition of $20 \mu \mathrm{g}$. chloramphenicol per $\mathrm{ml}$. to the incubation medium, samples for viable counts were taken without any attempt to remove the drug because it appeared to be purely bacteriostatic (rather than bactericidal). It was found that the dilutions necessary were sufficient to decrease the concentration of the drug below that causing reduction in viability, although the colonies were slightly smaller in size.

In some experiments the number of bacilli per 'unit' (chain of bacilli) was recorded microscopically as the number of individual bacilli (recognized by the formation of complete cell-wall septa) in each of 100 separate units.

Optical density. The absorption of bacterial suspensions was measured at $675 \mathrm{~m} \mu$ and expressed as $\mathrm{mg}$. dry bacterial $\mathrm{wt} / \mathrm{ml}$. by reference to a standard dry $\mathrm{wt} /$ turbidity curve for Bacillus cereus 569.

\section{RESULTS}

\section{Properties of the unstable micros}

Origin. Although the original unstable micro mutant strain, 569/H/14 was isolated after treatment of its parent strain with EMS (see methods) similar mutants have been obtained spontaneously at apparently very high rates from strain $569 / \mathrm{H}$ after repeated subculture in liquid media.

Indeed, penicillinase-loss mutants of various kinds have been repeatedly isolated from cultures of strain 569/H during prolonged growth (e.g. six or more consecutive subcultures entailing inoculation of one loopful into $7.5 \mathrm{ml}$. of broth, each incubated for $24 \mathrm{hr}$ or more at $35^{\circ}$ with shaking). Table I summarizes the numbers in the various categories isolated in a series of three separate experiments. Most of those 
isolated (including the unstable micros) showed no measurable penicillinase activity (i.e. less than 0.5 units $/ \mathrm{mg}$. dry bacterial wt, which is the lower limit of the Perret assay method) and all (also including the unstable micros), except four out of the 59 tested, retained the strict constitutivity of the parent strain.

Table I. Numbers and types of spontaneous penicillinase-'loss' mutants from the magno constitutive Bacillus cereus mutant strain $569 / \mathrm{H}$

$$
\begin{aligned}
& \text { Class of 'loss' } \\
& \text { mutant }
\end{aligned}
$$

Magno-inducible

(wild-type revertant)

Meso-constitutive

Micro-constitutive

Negative (stable)

Negative (unstable)

(569/H/14 micro types)
Differential rate of enzyme formation (units/mg. dry bact.wt)

$\begin{array}{lr}>3.0 \text { units/mg. } & 8 \\ 0.5-3.0 \text { units/mg. } & 8 \\ <0.5 \text { units/mg. } & 37 \\ <0.5 \text { units/mg. } & 2\end{array}$

Total $\quad 59$

Table 2. Phenotypic properties of Bacillus cereus strains 569/H,

\begin{tabular}{|c|c|c|c|}
\hline & \multirow[b]{2}{*}{$569 / \mathrm{H}$} & \multicolumn{2}{|c|}{$569 / \mathrm{H} / \mathrm{I} 4$} \\
\hline & & Micro & Magno \\
\hline Lecithinase & +++ & +++ & +++ \\
\hline Amylase & + & + & + \\
\hline Proteinase & ++ & ++ & ++ \\
\hline $\begin{array}{l}\text { Nitrate reduction (to } \\
\text { nitrite) }\end{array}$ & ++ & ++ & ++ \\
\hline $\begin{array}{l}\text { Alkaline phosphatase } \\
\text { (repressed by inorganic } \\
\text { phosphate) }\end{array}$ & + & + & + \\
\hline Urease & - & - & - \\
\hline $\begin{array}{l}\alpha \text {-glucosidase (inducible } \\
\text { by maltose) }\end{array}$ & + & + & + \\
\hline Voges-Proskauer test & + & + & + \\
\hline Sugar fermentations & & & \\
\hline Salicin & + & + & + \\
\hline Glucose & + & + & + \\
\hline Arabinose & - & - & - \\
\hline Lactose & - & - & - \\
\hline Sucrose & + & + & + \\
\hline Maltose & - & - & - \\
\hline Xylose & - & - & - \\
\hline $\begin{array}{l}\text { Penicillin sensitivity } \\
\text { (units/ml.) }\end{array}$ & 10 & 0.0075 & $7 \cdot 5$ \\
\hline $\begin{array}{l}\text { Differential rate of } \\
\text { penicillinase formation } \\
\text { (units/mg. dry bact. wt) }\end{array}$ & 2500 & $<0.5$ & 1800 \\
\hline
\end{tabular}
569/H/I4 (micro and magno)

All the above tests, except where indicated otherwise, were carried out according to methods described by Cruickshank (I965). Alkaline phosphatase and $\alpha$-glucosidase assayed under conditions described by Torriani (1960) and Pollock (196I) respectively: proteinase as described by Smith, Gordon \& Clark (1952) using 'Marvel' as sourc eprotein and amylase by observing decolorized zones around colonies growing on nutrient agar (AA) containing $0.5 \%$ starch, subsequently ‘developed’ with I \% iodine solution. 
Two further, separately-isolated magno-constitutive mutant strains, $569 / \mathrm{K}$ and $569 / \mathrm{M}$, showed the same tendency to throw off loss mutants on subculture, whereas the semi-constitutive mutant (569/A, see Pollock, 1957) and a meso-constitutive (569/L) appeared completely stable.

Cultures of strain $569 / \mathrm{H} / \mathrm{I} 4$ produced no detectable penicillinase activity before magno-type convertants began to appear. Apart from the absence of penicillinase there were no demonstrable biochemical morphological or specific growth character differences between it and the parent strain $569 / \mathrm{H}$; nor was the magno (convertant) from $569 / \mathrm{H} / \mathrm{I} 4$ distinguishable phenotypically from the original parent $569 / \mathrm{H}$ (see Table 2). However, the similarity did not extend to the genotypic character determining the types of penicillinase-loss variants appearing on continuous subculture. At $35^{\circ}$, subcultures of $569 / \mathrm{H}$ and 569/H/I4-magno showed no differences, most of the loss mutants being stable. At $25^{\circ}$, however, cultures of 569/H/I4-magno yielded a much higher proportion of unstable micro variants (in one experiment, 100\%) than was obtained from $569 / \mathrm{H}$, which behaved as at $35^{\circ}$. It seems likely therefore that the failure to demonstrate the greater tendency of $569 / \mathrm{H} / \mathrm{I} 4$ convertants to produce unstable micros at $35^{\circ}$ was due to much higher spontaneous rate of conversion from unstable micros to relatively stable magnos at the higher temperature, leading to selection in favour of stable micros. This emphasizes the truly reversible, albeit polarized, nature of the micro to magno conversion.

Penicillin sensitivity. The penicillin resistance of individual bacilli from a 569/H/I 4 micro culture was, like that of stable micro-constitutives, very low (approx. 0.or units/ $\mathrm{ml}$.). By contrast, bacilli converted to the magno state had the same high resistance as the parent strain 569/H (over I0.0 units/ml., i.e. more than I000 times greater).

During conversion, resistance rapidly increased towards the $569 / \mathrm{H}$ level, along with an ultimate comparable increase of at least 3000 -fold: 0.5 to $1800 \mathrm{units} / \mathrm{mg}$. dry wt, in the differential rate of penicillinase formation.

Co-ordinate production of the two $\beta$-lactamases. Cephalosporinase (' $\beta$-lactamase II') activity has recently (Kuwabara \& Abraham, 1967) been shown in this strain to be due to a species of protein quite distinct from penicillinase ( $\beta$-lactamase I). Nevertheless both activities are induced co-ordinately in the wild type (Crompton, Jago, Crawford, Newton \& Abraham, 1962; M. R. Pollock, unpublished observations). In addition we have found a co-ordinate increase in both activities following conversion of $569 / \mathrm{H} / 14$ from the micro to the magno state: the cephalosporinase activity of the $569 / \mathrm{H}$ parent strain, and of $569 / \mathrm{H} / \mathrm{I} 4$ during and after the conversion, was always from $5 \%$ to $7 \%$ of the benzylpenicillinase activity.

Effect of sporulation. Sporulation appeared not to have any effect on the properties of 569/H/I4. The degree of genetic instability (i.e. speed and conditions of conversion from the micro to the magno state) and the actual percentage magnos present in the population at any given time were not significantly altered after preparation of a spore suspension by heating a $48 \mathrm{hr}$ old broth culture for $60 \mathrm{~min}$. at $60^{\circ}$ and subsequent washing of the organisms as previously described (Pollock, 1953a).

All-or-none effect. The difference between the micro and magno states of 569/H/14 was generally clear cut and of the 'all-or-none' type. Colonies derived from 569/H/I4 grown in or on AA overnight at $25^{\circ}$ or $30^{\circ}$ and developed with penicillin at room temperature (see Methods) were either white (unchanged) or bright red (due to penicilloic acid production). 
Colonies derived from a culture of $569 / \mathrm{H} / \mathrm{I} 4$ in the micro state were shown to be pure: they yielded $100 \%$ white colonies after re-spreading on AA plates and analysis (see Methods) at $25^{\circ}$. However, if the same original culture were grown in AA at $35^{\circ}$, a significant proportion of developing colonies were found on analysis to be mixed (usually with reds very much in the minority). This suggests that spontaneous conversion from micro to magno had occurred in these colonies during growth. The effect was more marked at $40^{\circ}$, when nearly all colonies (whether scored as white or red) proved to be mixed. Population analyses of colonies indicated that they would be likely to be scored as red if their populations consisted of more than $15 \%$ bacilli already in the magno state (i.e. giving rise to red colonies even at $25^{\circ}$ ).

These tests show that the danger of spontaneous intra-colonial conversion during growth in AA vitiating the results of a population analysis could be avoided by not employing an incubation temperature above $30^{\circ}$.

Broth subcultures from white colonies (identified through velvet pad replica plates in order to avoid contact with penicillin) incubated at $35^{\circ}$ had detectable penicillinase activity only to the extent expected from the small (but variable) proportion of magno type cells they sometimes contained (as indicated by the proportion of red colonies appearing on further subculture and analysis on AA plates).

Broth subcultures from red colonies (similarly isolated in the absence of penicillin) generally consisted of $100 \%$ magno-type cells and produced enzyme at the full differential rate expected of the $569 / \mathrm{H}$ parent type. An important exception to this general rule will be discussed later.

\section{Kinetics}

\section{Characteristics of the conversion reaction}

At $45^{\circ}$. Environmentally stimulated appearance of magno varieties from $569 / \mathrm{H} / 14$ micros was first observed by noticing the increased number of red colonies (on AA after developing with penicillin) appearing after incubation at $42^{\circ}$ instead of $35^{\circ}$ and the almost complete stability of the micro variety during growth at $25^{\circ}$. It was then found that incubation of a broth culture of $569 / \mathrm{H} / \mathrm{I} 4 \mathrm{micros}$ at $45^{\circ}$ provoked up to $100 \%$ conversion to the magno state in less than $2 \mathrm{hr}$ (Fig. I).

Although not shown in Fig. I, incubation of an aliquot culture from the same micro-type colony at $35^{\circ}$ involved no conversion to the magno state during the $3 \mathrm{hr}$ of the experiment. Neither the wild-type strain 569 nor other micro-constitutive strains derived from $569 / \mathrm{H}$ showed any tendency to give rise to magnos during growth at $45^{\circ}$.

Although the total viable count and turbidity increased steadily throughout the experiment, the switch to the magno state occurred suddenly, after an absolute lag of 80 to $90 \mathrm{~min}$. and was practically complete after a further hour. The $50 \%$ conversion point (the time to reach $50 \%$ of the maximum number of convertants) usually occurred between 90 and $120 \mathrm{~min}$. after transfer to $45^{\circ}$. The amount of growth at $45^{\circ}$, measured either as increase in optical density or total count, was found to vary considerably from one experiment to another-largely no doubt because this temperature is critical, being at the extreme upper limit for growth of the Bacillus cereus 569 family. However, the kinetics and degree of conversion seemed to be quite unrelated to the extent of growth, even in certain experiments where there was a net drop in viable count. 
Figure I also shows that detectable penicillinase activity appeared at the same time as the increase in the magno count and thereafter rapidly increased to a final level (approx. 1800 units/mg. dry bact. wt, not shown in Fig. I) not much below that (2500 units $/ \mathrm{mg}$.) expected of a typical culture of $569 / \mathrm{H}$.

With chloramphenicol. Addition of $20 \mu \mathrm{g}$. chloramphenicol $/ \mathrm{ml}$. to the culture during incubation at $35^{\circ}$ was unexpectedly found also to induce up to $100 \%$ conversion of a 569/H/14 micro culture with similar kinetics (Fig. 2). However, results with chloramphenicol were not so quantitatively reproducible as those involving conversion at $45^{\circ}$.

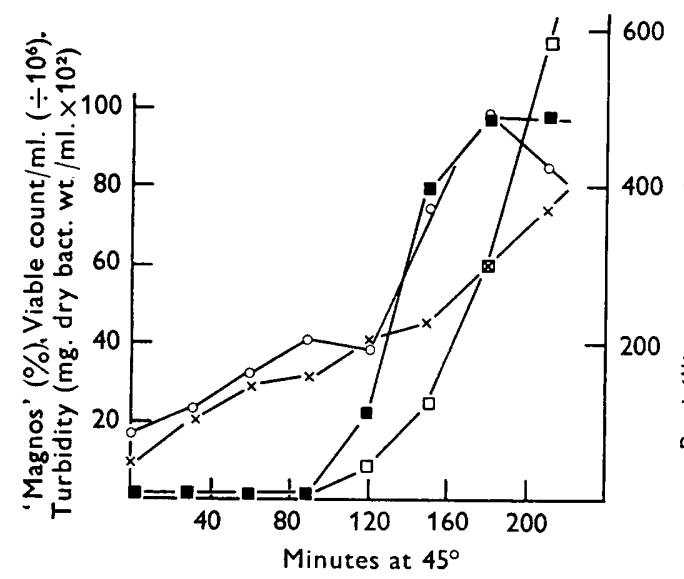

Fig. I

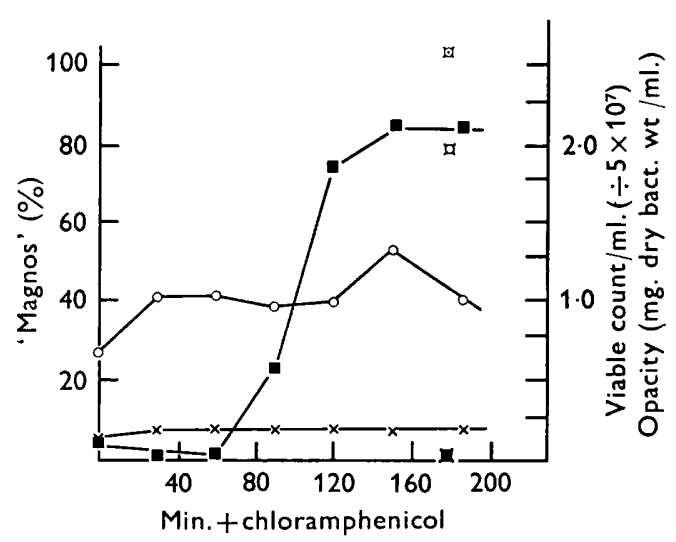

Fig. 2

Fig. I. Complete genotypic and phenotypic conversion of a population of Bacillus cereus $569 / \mathrm{H} / \mathrm{I} 4$ from the non-penicillinase producing micro state into the fully derepressed penicillinase-producing magno state, by incubation at $45^{\circ} . \times-\times$, Optical density of culture; $\bigcirc-\bigcirc$, total viable count; $\square-\square$, magnos: as $\%$ of total count; $\square-\square$, penicillinase activity units $/ \mathrm{ml}$.

Fig. 2. Genotypic conversion of a population of Bacillus cereus $569 / \mathrm{H} / \mathrm{r} 4$ from the micro to the magno state by incubation at $35^{\circ}$ in the presence of chloramphenicol $(20 \mu \mathrm{g} . / \mathrm{ml}$.). $\times-x$, optical density; $\bigcirc-0$, total viable count; $\square$, magnos: as $\%$ of total count; $\not{a}, \mathcal{Q}, \boldsymbol{X}=$ points respectively indicating optical density, total viable count and magnos as $\%$ of total count of a control culture incubated similarly without chloramphenicol.

Variations in the magno colony count according to the temperature of incubation of the inoculated AA plates suggested that residual chloramphenicol, perhaps bound to the cells, was continuing to act in stimulating conversion after plating out samples. Washing the bacilli free of the drug caused no significant differences; and it was not possible immediately to reverse its inhibitory effect on growth by such treatment (nor could enzyme formation by an apparently converted population be demonstrated during the first $2 \mathrm{hr}$ after treatment), although the viable count was unaffected. It is clear therefore that there is considerable growth lag after plating out chloramphenicoltreated organisms, and during this time a critical event, essential for conversion, may take place.

Phenotypic lag and development of penicillin resistance. A comparison between enzyme production and the appearance of magno-type colonies shown in Fig. I indicate that there can be little, if any, lag between the time when a bacillus is committed to reproduce in the magno state and when it begins to produce enzyme at the full, de-repressed rate. 
Penicillin-resistance of individual cell units can also be measured. This has been done using final concentrations of $0 . \mathrm{I}$ and $\mathrm{I} \cdot 0$ units of benzylpenicillin per $\mathrm{ml}$. in the agar plates. These levels can be shown, in reconstruction experiments with mixtures from cultures of stable micro and magno strains, to inhibit completely the growth of micro-type cells into colonies, whilst allowing normal growth of $569 / \mathrm{H}$ and other magno-types.

Table 3. Development of penicillin resistance in Bacillus cereus 569/H/14 (micro-type) during conversion to the magno-type by incubation in broth at $45^{\circ}$

\begin{tabular}{|c|c|c|c|c|c|c|c|}
\hline \multirow{2}{*}{$\begin{array}{l}\text { Plating-out } \\
\text { medium }\end{array}$} & & \multicolumn{6}{|c|}{$\begin{array}{c}\text { Viable counts }\left(\div 10^{7}\right) \text { per ml. at the following times (min.) } \\
\text { after transfer from } 35^{\circ} \text { to } 45^{\circ}\end{array}$} \\
\hline & & 0 & 45 & 80 & 105 & I40 & 200 \\
\hline \multicolumn{8}{|l|}{ Plain nutrient agar (AA) } \\
\hline Total & & $2 \cdot 4$ & $5 \cdot 0$ & $13 \cdot 0$ & 19 & 24 & 35 \\
\hline Magno-type & & - & - & 0.6 & 4.9 & $24 \cdot 5$ & 34 \\
\hline $\begin{array}{l}\mathrm{AA}+\mathrm{O} \cdot \mathrm{I} \text { unit } \\
\text { benzylpenicillin } / \mathrm{ml} .\end{array}$ & Total* & 0.0026 & 0.004 & 0.75 & $9 \cdot 0$ & 24 & 35 \\
\hline $\begin{array}{l}\mathrm{AA}+\mathrm{I} \cdot 0 \text { unit } \\
\text { benzylpenicillin } / \mathrm{ml} \text {. }\end{array}$ & Total* & 0.00032 & 0.004 & $I \cdot 0$ & $9 \cdot 0$ & 22 & 34 \\
\hline
\end{tabular}

* All colonies developing on penicillin agar were of the magno-type.

Table 3 shows the comparative micro and magno counts on plain AA and on penicillin AA during a conversion experiment at $45^{\circ}$. On penicillin plates the total numbers of colonies developing (all of which were of the magno type) corresponded to the numbers of magno type colonies appearing on the plain agar plates. After I $40 \mathrm{~min}$. these represented practically I00\% of the total viable count.

This experiment confirms the rapid phenotypic expression of the conversion and shows that all the converted cells must be immediately capable of forming the enzyme approximately equally and at maximal rate.

\section{Significance of mixed colonies}

It was discovered that during the early stages of induced conversion a proportion of the colonies scored as red proved, on subsequent analysis, to be mixed (defined as containing not more than $95 \%$ of the predominant type). Most of these mixed colonies contained roughly equal proportions of reds and whites. At least 100 colonies were analysed from each sample except towards the end of the conversion experiment when the proportion of reds had passed $50 \%$ and only 50 were tested.

The proportion of mixed colonies in general declined as conversion of the population proceeded. Figure 3 shows the relationship between the number of such mixed reds as a proportion of total reds and the total reds as a proportion of the total colony count in a series of four experiments on conversion induced at $45^{\circ}$.

It could, of course, be argued that these mixed reds result from conversions occurring after plating out into AA and that, for this reason, the kinetics of induced conversion as followed in this work may be very inaccurate. It has already been argued that this could be true for conversions induced by chloramphenicol and, for this reason, these have been excluded from the results summarized in Fig. 3. But this argument is unlikely to apply to conversion at $45^{\circ}$ because in this case there is no significant phenotypic lag in the expression of conversion (measured either in the form 
of penicillinase production or as development of penicillin-resistance)—as indicated in Fig. I and Table 3.

One explanation of the decreasing proportion of mixed red colonies found during conversion would be that they reflect the diminishing proportion of multi-cell units containing unconverted cells in a population where the conversion event occurred randomly in individual cells. Although there was considerable variation between experiments and during the conversion process, Table 4, summarizing the results of the four experiments illustrated in Fig. 3, shows that a mean of only a little under

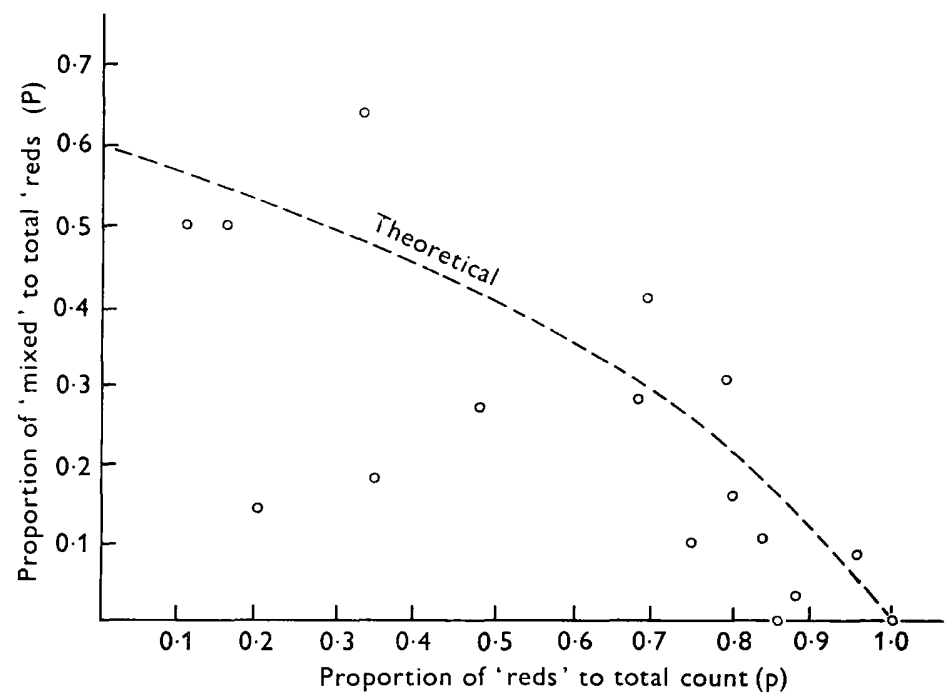

Fig. 3. The proportion of mixed colonies (i.e. appearing on plates as 'reds' (magnos) but subsequently proving on analysis to consist of micro and magno cells), $\mathrm{P}$, occurring during conversion of populations of Bacillus cereus $569 / \mathrm{H} / \mathrm{I} 4$ from the micro to the magno state induced by incubation at $45^{\circ}$ (in a total of four separate experiments), expressed in relation to the proportion of recorded 'reds' in the total viable count $(\mathrm{p}) .---$, Theoretical curve expected on the basis of conversion occurring at random in each cell and the observed mean proportion of double cell units in the population (see text).

Table 4. Mean numbers of bacilli per chain ('unit') in cultures of Bacillus cereus 569/H/I4 during conversion at $45^{\circ}$

\begin{tabular}{cccc} 
& \multicolumn{3}{c}{ Units in following classes $(\%)$} \\
\cline { 2 - 3 } $\begin{array}{c}\text { Expt. } \\
\text { no. }\end{array}$ & One bacillus & Two bacilli & $\begin{array}{c}\text { More than } \\
\text { two bacilli }\end{array}$ \\
I & 58 & 33 & 9 \\
2 & 64 & 33 & 3 \\
3 & 54 & $4 \mathrm{I}$ & 5 \\
4 & $5 \mathrm{I}$ & 43 & 6 \\
$\begin{array}{c}\text { Over-all } \\
\text { range }\end{array}$ & $5 \mathrm{I}-64$ & $33-43$ & $3-9$ \\
$\begin{array}{c}\text { Over-all } \\
\text { mean }\end{array}$ & 57 & 37 & 6
\end{tabular}

Mean numbers of bacilli per 'unit', in roo unselected units in up to seven samples taken sequentially from each culture during $180 \mathrm{~min}$. incubation at $45^{\circ}$ were recorded and results expressed as percentages in each class. 
$50 \%$ of units contained more than one cell and that over $85 \%$ of these multi-cell units contained only two cells. Suppose that the proportions of two-cell and one-cell units were equal and three- (or more) cell units negligible, two-thirds of the conversion events, if randomly distributed amongst individual cells, would yield mixed red colonies at the very beginning of the conversion process.

The actual proportions of mixed red colonies to be expected on this hypothesis can be calculated accurately from the following formula (for which we are much indebted to Dr J. F. Collins), making only the simplifying approximation of including the few more-than-two-cell units within the two-cell unit group.

$$
P=\frac{2 a-2+2 x}{a+\mathrm{I}+x},
$$

where $x= \pm \sqrt{ }\left[(\mathrm{I}+a)^{2}-4 a p\right], a$ being the proportion of units containing two cells, $p$ the proportion of all colonies that are 'red' and $P$ the proportion of red colonies that prove to be mixed.

The theoretical curve in Fig. 3, giving expected values for $P$, has been calculated thus from the data summarized in Table 4 (giving a value of 0.43 for $a$ ) and the progress of conversion $(P)$ during the same four experiments.

The scatter of points is high but the general trend suggests that the hypothesis of random conversion at the cell level is not unreasonable.

\section{The metabolic basis of conversion}

Phase and extent of growth. It was found that if treatment with chloramphenicol or at $45^{\circ}$ was delayed until growth level had reached $0.05 \mathrm{mg}$. dry bacterial wt $/ \mathrm{ml}$., conversion was significantly retarded. After a level of $0.2 \mathrm{mg} . / \mathrm{ml}$., no conversion was detected for up to $3 \mathrm{hr}$.

If bacilli were removed from the growth medium and resuspended in phosphate alone, conversion - either with chloramphenicol or at $45^{\circ}$-was greatly reduced.

Although growth-measured either by viable count or opacity increase-is clearly not essential for conversion (as demonstrated by the effect of chloramphenicol and by those experiments at $45^{\circ}$ where little growth took place) it must be concluded that fairly complex metabolic events underlie the phenomenon.

Inhibitors and other promoters of conversion. Other inhibitors of protein synthesis were tested under conditions identical to those used with chloramphenicol, but gave relatively slight and somewhat variable stimulation as follows:

Streptomycin (Io $\mu \mathrm{g} . / \mathrm{ml}$ ) gave $7.5 \%$ conversion, puromycin (24 and $94 \mu \mathrm{g} . / \mathrm{ml}$.) up to $15 \%$, and actinomycin D $(3.3 \mu \mathrm{g}$. $/ \mathrm{ml}$.) up to $40 \%$, all against a control value of not more than I \% and conversion with chloramphenicol of up to $100 \%$. None of these compounds had any effect on the extent or kinetics of conversion in the presence of chloramphenicol. Known inhibitors of DNA synthesis, mitomycin C (0.01 $\mu \mathrm{g} . / \mathrm{ml}$.), caffeine $(4.8$ and $9.7 \mathrm{mg} . / \mathrm{ml}$.) FUDR $(25 \mu \mathrm{g} . / \mathrm{ml}$.) and nalidixic acid (10.0 and Ioo $\mu \mathrm{g} . / \mathrm{ml}$.) had no effect by themselves (except that both mitomycin and FUDR were very toxic and caused a significant reduction in the viable count). But nalidixic acid (10 $\mu \mathrm{g} . / \mathrm{ml}$.), if added during treatment at $45^{\circ}$, caused inhibitions of conversion from $70 \%$ to $98 \%$ after $3 \mathrm{hr}$ treatment, usually without causing significant loss of viability.

In whatever manner the possible role of DNA synthesis may be assessed, results with chloramphenicol and treatment at $45^{\circ}$ strongly support the idea that some 
protein repressor substance must control the rate of conversion in normal cultures of $569 / \mathrm{H} / \mathrm{I} 4$.

The conversion-promoting effect of incubation at $45^{\circ}$ could be explained if it is supposed that in $569 / \mathrm{H} / 14$ this protein repressor of conversion is somewhat thermolabile.

The two types of treatment that promote conversion-incubation at $45^{\circ}$ and incubation with chloramphenicol at $35^{\circ}$-would, on this hypothesis, operate towards the same end (elimination of the same protein) by very different means: the former by inactivating the protein and the latter by preventing its formation. The pre-conversion lag could, in most instances, be due to the time necessary to allow the concentration of this protein repressor to fall below a critical, effective level.

Unlike the effect of combined addition of two different inhibitors of protein syn-

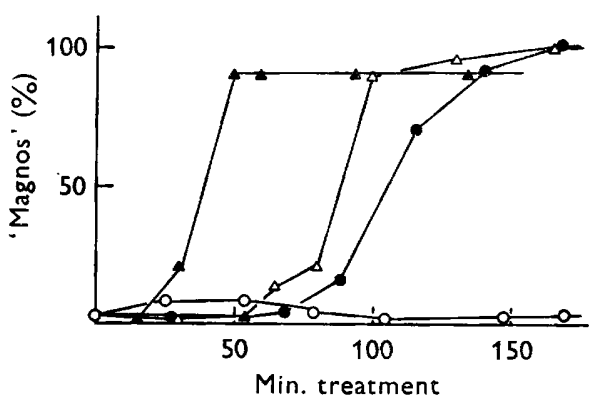

Fig. 4

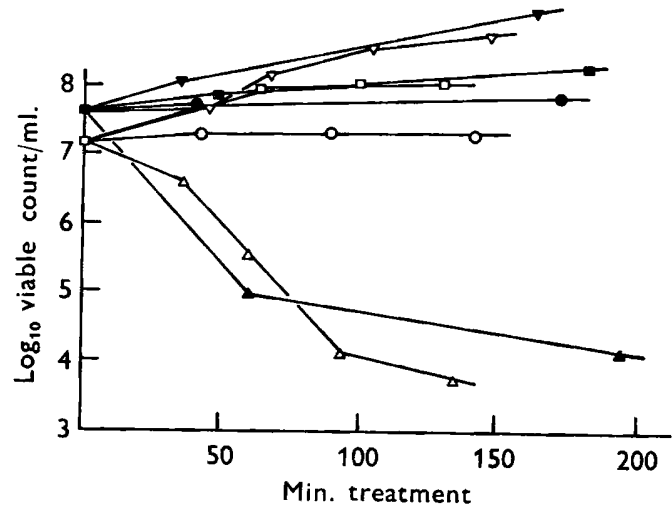

Fig. 5

Fig. 4. Synergistic effect of addition of chloramphenicol and incubation at $45^{\circ}$ in shortening the lag for the genotypic conversion of $569 / \mathrm{H} / \mathrm{I} 4$ from the micro to the magno state. All results expressed as \% magnos in total viable count. $\mathrm{O}-\mathrm{O}$, Control (incubation at $35^{\circ}$ without chloramphenicol); $-\longrightarrow, 35^{\circ}+$ chloramphenicol $\left(20 \mu \mathrm{g} . / \mathrm{ml}\right.$.); $\triangle \longrightarrow \triangle, 45^{\circ}$, no chloramphenicol; $\Delta-\Delta, 45^{\circ}+$ chloramphenicol $(20 \mu \mathrm{g} . / \mathrm{ml}$.).

Fig. 5. Comparative effects of incubation at $35^{\circ}$ and $45^{\circ}$, with and without chloramphenicol, on the viable counts of the micro and magno varieties of Bacillus cereus 569/H/I4. Open symbols: micro type; filled symbols: magno type. $\nabla, 35^{\circ}$ (no chloramphenicol); $\square, 45^{\circ}$ (no chloramphenicol); $\bigcirc, 35^{\circ}+$ chloramphenicol $(20 \mu \mathrm{g} . / \mathrm{ml}.) ; \Delta, 45^{\circ}+$ chloramphenicol (20 $\mu \mathrm{g} . / \mathrm{ml}$.).

thesis, treatment at $45^{\circ}$ and treatment with chloramphenicol should be powerfully synergistic in their effect and lead to a shortening of the pre-conversion lag. Figure 4 gives the results of an experiment showing that the predicted synergism did indeed occur in a very marked manner. The lag was reduced by over $70 \%$-from around $75 \mathrm{~min}$. to $20 \mathrm{~min}$. - and the $50 \%$ conversion time was more than halved.

Unfortunately, whereas neither $45^{\circ}$ nor chloramphenicol by themselves generally caused decrease in viability, the combined effect of both was markedly bactericidal, the counts falling to one-tenth the original level by the time conversion was completed. Although there was still a significant absolute increase in magno count during the earlier stages of the experiment, thereafter there was a decrease and it is possible formally to argue that some selection of magnos could have occurred.

That this is not indeed the case is shown in Fig. 5 where the comparative counts of 
micros (during conversion) and of mature magnos (after conversion) treated under the same conditions do not differ significantly. This shows that the two varieties are equally sensitive to the traumatic effects of incubation with chloramphenicol at $45^{\circ}$.

\section{DISCUSSION}

A satisfactory interpretation of this phenomenon must await the development of a more precise system for the study of genetics in Bacillus cereus. Until very recently the many attempts made with this species have not borne fruit and claims to have demonstrated transformation (Felkner \& Wyss, 1964) have not been substantiated (Goldberg \& Gwinn, 1968). However, now that a generalized transducing phage for $B$. cereus has been discovered and successfully applied by Thorne (1968), it may be hoped some progress may at last be made in the genetics of this recalcitrant organism.

Until then it must be accepted that it is not even possible to characterize the genetic event underlying the original mutation from the wild-type inducible strain 569 to the magno-constitutive $569 / \mathrm{H}$, let alone the basis of the loss mutation which gave rise to the unstable $569 / \mathrm{H} / \mathrm{I} 4$ micro strain or the conversion phenomenon itself.

However, even now it may be supposed that the reversibility of the micro to magno conversion makes it rather unlikely that the switch simply involves a loss (deletion) of a unique genetic element (e.g. an extrachromosomal plasmid) forming a repressor of the penicillinase structural gene. Beyond that, possible hypotheses-none of which can yet be excluded-group themselves into three broad classes as follows:

(I) Metabolic switches of the Delbrück (1949) model type or cycles not involving heritable modification of DNA (Pollock, I953 $b$; Monod \& Jacob, 1961). Such possibilities probably cannot be formally excluded until the micro or magno states can be separately transferred from one organism to another, though they are made unlikely by the persistence of these distinct states through the sporulation cycle.

(2) Consistent errors or alterations occurring at a specifically relevant locus during chromosome replication. Since the individual cells of most two-cell units (as recorded in Table 4) are presumably derived from a common mother cell and therefore synchronized for cell division, it might be argued that a truly random occurrence of conversion amongst organisms joined in pairs would be evidence against the possibility of conversion being associated with the replication of a specific locus on the chromosome. However, although the kinetics of the appearance of mixed colonies during conversion hints at the possibility of a random occurrence at the cell level, it is no more than suggestive and in any case the above argument holds only if it can be shown either that Bacillus cereus cells have but a single chromosome or that, if more than one is present, their replication is synchronous.

(3) Position effects, involving translocations or duplications of genetic regions whereby controlling elements are separated from, or brought into contiguity with, the structural gene they regulate, causing a switching on or off of production of the relevant enzyme: in this case penicillinase. In so far as such a recombination may involve synthesis of DNA, the antagonistic effect of nalidixic acid, a known inhibitor of DNA formation (Goss, Dietz \& Cook, I964; Cook, Brown, Boyle \& Goss, I966; Barbour, 1967), on conversion gives some support to the above interpretation. This type of hypothesis may be difficult to prove (or exclude) even with sophisticated genetic techniques. But it is one-in various forms-which seems to be naturally well favoured at the moment as a basis for the interpretation of unstable genetic states in Aspergillus 
studied by Bainbridge \& Roper (I966) and Nga \& Roper (I968), in Antirrhinum by Fincham (1967) and of those involving the $\mathrm{Gal}_{3}$ locus in Escherichia coli as reported by Morse (1967) and of both the pro - 40I locus (Smith-Keary \& Dawson, 1964) and antigenic phase variation in Salmonella (B. A. D. Stocker, private communication), as well of course as the complicated variations of control of characters in maize (particularly anthocyanin production) worked out by McClintock (196I). All these phenomena may eventually be found to share some common molecular mechanism. And their possible relevance to mechanisms for tissue differentiation and antibody formation in higher organisms cannot be ignored.

What could in fact be a special case of the above hypothesis might be considered in the light of the possibility, suggested recently by the work of Fraser, Baird \& Kleeman (1969), that Bacillus cereus may, under certain circumstances, be diploid. An unstable situation might arise if only one of the chromosomes in a pair was actively expressed at any one moment, as for the $X$ chromosomes in female mammals and other instances in higher organisms (see Lyon, 1968). Conversion could then be a reflexion of a switch over of the active state from one chromosome to the other in a pair heterozygous for penicillinase formation. An explanation based on simple segregation to the haploid state would be excluded because conversion involves $100 \%$ of the cells and is anyway not completely irreversible.

Whatever may be the nature of the event underlying this conversion phenomenon it would appear to be under the control of a protein repressor which, at least in the case of strain $569 / \mathrm{H} / \mathrm{r} 4$ (micro), is thermo-labile. Unless the reverse change from magno to micro is due to some quite different type of event, it must be supposed that this thermolability is lost in the conversion process. Restoration of a stable repressor might therefore be coupled with restoration of activity to the penicillinase gene and be part of the same phenomenon.

We are grateful to Miss Kathleen O'Hare and Miss Alexis Smith for technical assistance during summer vacations, and to Dr J. F. Collins for helpful discussions and for calculating the formula on which the theoretical curve illustrated in Fig. 3 is based.

The senior author (M.R.P.) is Honorary ${ }_{\text {s. }}$ Director of a Research Group on 'Bacterial Enzyme Variation' supported by the Medical Research Council.

\section{REFERENCES}

BAINBRIDGe, B. W. \& Roper, J. A. (1966). Observations on the effects of a chromosome duplication in Aspergillus nidulans. J. gen. Microbiol. 42, 417.

BARbour, S. D. (1967). Effect of nalidixic acid on conjugational transfer and expression of episomal lac genes in Escherichia coli $\mathrm{K} \mathbf{1 2}$. J. molec. Biol. 28, 373.

BrINK, R. A. (1964). Genetic repression in multicellular organisms. Amer. Nat. 98, 193.

Brink, R. A., Styles, E. D. \& Axtell, J. D. (I968). Paramutation: directed genetic change. Science, N.Y. I59, I6I.

Collins, J. F., Mandelstam, J., Pollock, M. R., Richmond, M. H. \& Sneath, P. H. A. (I965). A suggested phenotypic classification and terminology for enzyme mutants in micro-organisms. Nature, Lond. 208, 841.

Cook, T. M., Brown, K. G., Boyle, J. V. \& Goss, W. A. (1966). Bactericidal action of nalidixic acid on Bacillus subtilis. J. Bact. 92, 1510.

Crompton, B., Jago, M., Crawford, K., Newton, G. G. F. \& Abraham, E. P. (1962). Behaviour of some derivatives of 7-amino-cephalosporanic acid and 6-amino penicillanic acid as substrates, inhibitors and inducers of penicillinases. Biochem. J. 83, 52 . 
CRUICKSHANK, R. (editor) (1965). Medical Microbiology, I I th edn. Edinburgh and London: E. and S. Livingstone.

Dawson, G. W. P. \& Smith-Keary, P. F. (1963). Episomic control of mutation in Salmonella typhimurium. Heredity, Lond. $\mathbf{1 8}, \mathrm{I}$.

DelbRÜCK, M. (1949). Discussion in 'Unités biologiques douées de continuité génétique', p. 33. Ed. CNRS, Paris.

Dubnau, D. A. \& Pollock, M. R. (1965). The genetics of Bacillus licheniformis penicillinase: a preliminary analysis from studies on mutation and inter-strain and intra-strain transformations. J. gen. Microbiol. 41, 7.

FELKNER, I. C. \& WYSS, O. (I964). A substance produced by competent Bacillus cereus 569 cells that affects transformability. Biochem. biophys. Res. Comm. x6, 94.

FinchaM, J. R. S. (1967). Mutable genes in the light of Callan's hypothesis of serially repeated gene copies. Nature, Lond. 215, 864.

Fraser, D. K., BAIRD, J. P. \& KLEEMAN, J. M. (1969). Formation of heterozygotes in mixed cultures of B. cereus. Genetics, Princeton (in the Press).

Goldberg, I. D. \& GWIN, D. D. (I968). Transformation in Bacillus cereus: a critique. Biochem. biophys. Res. Comm. 31, 267.

Goss, W. A., Dietz, W. H. \& CooK, T. M. (1964). Mechanism of action of nalidixic acid on Escherichia coli. J. Bact. 88, I I $12 ; 89$, 1068.

Harrison, B. J. \& Fincham, J. R. S. (1967). Instability at the pal locus in Antirrhinum majus. 2. Multiple alleles produced by mutation of one original unstable allele. Heredity, Lond. 22, 21 I.

HAYEs, W. (1964). The Genetics of Bacteria and Their Viruses. Oxford: Blackwell.

Kogut, M., Pollock, M. R. \& TRIDGell, E. J. (1956). Purification of penicillin-induced penicillinase of Bacillus cereus NRRL 569: a comparison of its properties with those of a similarly purified penicillinase produced spontaneously by a constitutive mutant strain. Biochem. J. 62, 39I.

Kuwabara, S. \& Abraham, E. P. (1967). Some properties of two extracellular $\beta$-lactamases from Bacillus cereus $569 / \mathrm{H}$. Biochem. J. 103, $27 \mathrm{C}$.

Lyon, M. F. (1968). Chromosomal and subchromosomal inactivation. A. Rev. Genet. 2, 31 .

McClintock, B. (I96I). Some parallels between gene control systems in maize and in bacteria. Amer. Nat. 95, 265.

MCClINTOCK, B. (I965). The control of gene action in maize. Brookhaven Symp. Biol. 18, I62.

MoNOD, J. \& JACOB, F. (I96I). General conclusions: teleonomic mechanisms in cellular metabolism, growth and differentiation. Cold Spring Harb. Symp. quant. Biol. 26, 389.

MoRSE, M. L. (1967). Reversion instability of an extreme polar mutant of the galactose operon. Genetics, Princeton 56, 331.

NGA, B. H. \& RoPER, J. A. (I968). Quantitative intrachromosomal changes arising at mitosis in Aspergillus nidulans. Genetics, Princeton 58, 193.

Perret, C. J. (1954). Iodometric assay of penicillinase. Nature, Lond. 174, 1012.

Pollock, M. R. (1953a). Penicillinase adaptation and fixation of penicillin sulphur by Bacillus cereus spores. J. gen. Microbiol. 8, 186.

Pollock, M. R. (1953b). Stages in enzyme adaptation. Symp. Soc. gen. Microbiol. no. 3, 150.

Pollock, M. R. (1957). Penicillin-induced resistance to penicillin in cultures of Bacillus cereus. In Ciba Foundation Symp. on 'Drug Resistance in Micro-organisms', p. 78. Ed. by G. E. W. Wolstenholme and C. M. O'Connor. London: J. and A. Churchill, Ltd.

Pollock, M. R. (I96I). The measurement of the liberation of penicillinase from Bacillus subtilis. J. gen. Microbiol. 26, 239.

Pollock, M. R. \& Torriani, A. M. (1953). Purification et caractéristiques physico-chimiques de la pénicillinase de Bacillus cereus. C. r. Séanc Acad. Sci., Paris 237, 276.

Smith, N. R., Gordon, R. E. \& Clark, F. E. (1952). Aerobic spore forming bacteria. Agriculture Monogr. no. I6, p. 43 .

Smith-Keary, P. F. \& Dawson, G. W. P. (1964). Episomic suppression of phenotype in Salmonella Genet. Res. 5, 269.

ThORNe, C. B. (1968). Transducing bacteriophage for Bacillus cereus. J. Virol. 2, 657.

TORRIANI, A-M. (1960). Influence of inorganic phosphate in the formation of phosphatases by Escherichia coli. Biochim. biophys. Acta 38, 460. 